\title{
Eficiência de sistemas de aproveitamento de águas pluviais em municípios do estado do Rio Grande do Sul/Brasil
}

\section{Vanessa Sari, Lília Mayumi Kaneda Seeger Eloiza Maria Cauduro Dias de Paiva, Ana Lúcia Denardin da Rosa}

RESUMO: Essa pesquisa apresenta um estudo da eficiência (proporção do tempo em que o reservatório atende a demanda) de sistemas de aproveitamento pluvial para 30 estaçóes pluviométricas pertencentes a 16 municípios do estado do Rio Grande do Sul/Brasil. A metodologia proposta oferece uma visão interligada da influência dos diferentes constituintes do sistema de aproveitamento (volume do reservatório, área de captação e demanda), simulando o comportamento deste como um todo. A hipótese do trabalho admitiu atividades de uso não potável em indústrias de bebidas, bacias sanitárias de residências uni e multifamiliar e lavagem de veículos em postos de combustíveis, com a utilização de diferentes áreas de captação e volumes comerciais de reservatórios. Os resultados individuais para as eficiências dos sistemas de cada uma das 30 estaçóes revelou um comportamento muito semelhante àquele obtido pela utilização dos valores médios das eficiências. Existe um crescimento das eficiências (individuais e médias) em função do aumento do volume de armazenamento do reservatório (considerando-se a área constante) e em função do aumento da área de captaçáo (considerando-se o volume constante). Já a variação da eficiência média (diferença entre um dado valor de eficiência e seu valor subseqüente) diminuiu com o aumento da área para um volume constante em quaisquer das demandas simuladas. Entretanto, o mesmo não se pode afirmar a respeito dessa variação em relação ao aumento do volume para uma área constante, pois se por um lado existe uma tendência de diminuir essa variaçáo com o aumento do volume nas demandas em residência multifamiliar e em indústria, por outro, não existe uma tendência no caso da demanda em residência unifamiliar e postos de combustíveis. O método apresentado possibilita a visualização gráfica da eficiência a ser obtida nos sistemas de aproveitamento para determinada área de captação, volume de reservatório e demanda já implantada. Permite ainda, verificar as dimensóes a serem projetadas em termos de área de captação e volume de armazenamento, conhecida a demanda, para que se consiga atingir uma determinada eficiência pretendida. Os critérios apresentados e discutidos mostraram-se adequados resultando em eficiências consideravelmente satisfatórias ao atendimento parcial das demandas para fins não potáveis nos municípios analisados.

PALAVRAS-CHAVE: aproveitamento de águas pluviais; eficiência do sistema de aproveitamento.
ABSTRACT: This paper presents a study of the efficiency (proportion of time the tank supplies the demand) of rainwater utilization systems for 30 pluviometric stations belonging to 16 cities in the state of Rio Grande do Sul, Brazil. The proposed methodology offers a view of interconnected influences of different constituents of the rainwater utilization system (tank volume, catchment area and demand), simulating its behavior as a whole. The hypothesis of the study admitted activities of non-potable uses in a beverage industry, flushing toilets of single and multifamily housing and washing of vehicles at gas stations, with the use of different catchment areas and commercial tank volume. Individual results for the efficiencies of the systems for each of 30 stations showed a behavior very similar to that obtained by the use of average values from the efficiencies. There is an efficiency growth (individual and average) as a function of the increase of the tank volume, (assuming a constant catchment area) and in function of the increase of the catchment area (assuming a constant tank volume). On the other hand, the average efficiency variation (the difference between a given value of efficiency and its subsequent value) decreased with an increasing catchment area for a constant storage volume in any of the simulated demands. However, we cannot assure this change in relation to the volume increase for a constant catchment area, because even presenting a tendency to decrease this variation with the increasing storage volume for the demands in multifamily residence and industry, there is no tendency in the case of demand in single-family residences and gas stations. The method presented here permits to know the efficiency of the system for a known demand, a catchment area and a tank volume already implanted. We can also check the dimensions to be projected (catchment area and storage volume) for a specific demand and efficiency of the system. The criteria presented and discussed were adequate, resulting in considerable and satisfactory efficiencies to attend part of the demands for non-potable purposes in the cities analyzed.

KEYWORDS: rainwater utilization, efficiency of the utilization system. 


\section{INTRODUÇÃO}

Ao se considerar os desafios que afrontam os diversos países na luta pela garantia de um desenvolvimento econômico e social sustentável, a temática "ÁGUA" emerge como um ponto central de qualquer pauta. Escassez de água, deterioração da sua qualidade e impactos das inundaçóes estáo entre os problemas que requerem maior atenção e açáo imediata (Agarwal et al, 2000).

Fica então evidente a urgência da adoção de uma abordagem integrada e sustentável na gestão hídrica, que busque e viabilize fontes alternativas de suprimento aos fins menos nobres de sua utilização, uma necessidade básica em meio à priorização do uso da água disponível para garantir o atendimento do abastecimento público.

De fato, entre essas alternativas, o aproveitamento pluvial destaca-se por sua simplicidade e economia, concretizando-se como um dos meios viáveis de preservação desse recurso; além de contribuir para o controle de enchentes, um grave problema dos locais com amplas áreas impermeáveis (Annecchini et al, 2006).

Os sistemas de aproveitamento pluvial podem ser definidos como aqueles que captam a água da superfície na qual ela escoa, encaminham-na para um tratamento (quando necessário), para uma reservaçáo e posterior uso (Peters, 2006). Conforme Tomaz (2003), a economia de água pública estimada pela utilização desses sistemas é de aproximadamente $30 \%$.

Uma das dificuldades nessa modalidade de captação está justamente em projetar estruturas para coleta e armazenamento, de maneira a evitar o super dimensionamento no tamanho dos reservatórios ou na área de captação utilizada, bem como, a subutilização do sistema (Oliveira, 2004).

Boers e Ben-Asher (1982) relatam que o sucesso de um sistema de aproveitamento da água da chuva está relacionado, sobretudo, à quantidade de água captável pelo sistema e essa, por sua vez, varia conforme os componentes desse sistema (área de captação e volume de armazenamento), o índice pluviométrico da regiáo e o coeficiente de escoamento superficial.

Para Annecchini et al (2006) a adequada identificação da demanda a ser satisfeita, a correta escolha do tipo de reservatório de armazenamento, bem como, o cálculo das dimensóes mais apropriadas para esse reservatório, são também fatores fundamentais ao dimensionamento do sistema e à garantia da viabilidade técnica e econômica do projeto.

O dimensionamento oriundo de métodos tradicionais - baseados no conceito de regularização de vazão - em geral, leva ao super dimensionamento dos reservatórios de armazenamento e, por consequência, à inviabilidade construtiva desses sistemas. Métodos alternativos como aqueles que priorizam o máximo aproveitamento das águas no período mais chuvoso revelam-se, portanto atraentes e viáveis ao dimensionamento de tais sistemas de aproveitamento; sobretudo quando o uso da água captada destina-se ao elevado consumo industrial, traduzindo-se em uma considerável economia e rápido retorno do investimento realizado (Mierzwa et al, 2007).

Há que se considerar que em tais estudos é importante realizar uma análise da eficiência do sistema de aproveitamento, ou seja, determinar a proporção do tempo em que o reservatório atende a demanda. Além disso, é fundamental conhecer o potencial quantitativo de utilização da água da chuva, bem como, diagnosticar corretamente a demanda por água não potável e os volumes possíveis de serem captados.

Entretanto, a maioria dos trabalhos realizados tem como foco principal o dimensionamento do reservatório e não a análise da eficiência do sistema de aproveitamento como um todo. Alguns exemplos de estudos podem ser encontrados em: Fendrich (2002), Lopes (2002), May (2004), Oliveira (2004), Silva e Tassi (2005), Annecchini et al. (2006), Jaques et al (2006), Ghisi e Oliveira (2007), Ghisi et al (2007), Mierzwa et al (2007).

Herrmann e Schmida (1999) analisaram a eficiência de sistemas de aproveitamento pluvial em residência uni e multifamiliar na cidade de Bochum, Alemanha, apresentando diversos perfis gráficos. Os autores verificaram a viabilidade do aproveitamento em bacias sanitárias e quantificaram a influência desse sistema de aproveitamento sobre o sistema de drenagem urbana. Foram consideradas para efeito de cálculos a eficiência do sistema (porcentagem de água consumida que era proveniente do aproveitamento pluvial) e a eficiência da cobertura (porcentagem de água da chuva disponível para coleta que era efetivamente aproveitada). Os resultados encontrados mostraram que o aproveitamento pluvial reduz o consumo de água potável e minimiza o escoamento em excesso, facilitando o processo de drenagem. E esse benefício é mais significativo quando o sistema é implantado em edifícios com vários andares, em cidades densamente povoadas. 
Entretanto, salienta-se que o problema não se resume somente à avaliação quantitativa do sistema, mas também à qualitativa, estando os requisitos de qualidade e segurança sanitária diretamente relacionados ao uso para o qual se destina a água coletada: quando a água é para uso doméstico ela deve atender aos padróes de potabilidade que no Brasil são estabelecidos pela Portaria no 518 do Ministério da Saúde, de 25 de março de 2004.

O manual de Conservação e Reúso da Água em Edificaçóes (ANA, FIESP, SINDUSCON-SP, 2005) classifica as águas de reúso em quatro classes, especificando condições mínimas e padrôes de qualidade e sugere para os usos em descarga de bacias sanitárias, lavagem de pisos e fins ornamentais (chafarizes, espelhos de água etc.); lavagem de roupas e de veículos a classe 1, desta legislação.

Por outro lado, a Resolução CONAMA 357/05 (Brasil, 2005) sugere que a água utilizada para fins não potáveis (irrigaçáo de jardins, campos de esporte e lazer), com os quais o público possa vir a ter contato direto, deve atender os requisitos da classe 2 .

Com base nas considerações expostas, foi estudado um método alternativo para obtenção do dimensionamento da capacidade de reservatórios de armazenamento de águas pluviais, para fins não potáveis, em função da área de captação, demanda e eficiência do sistema.

\section{MATERIAIS E MÉTODOS}

Essa pesquisa foi desenvolvida no estado do Rio Grande do Sul/Brasil, contemplando o estudo de 30 estaçóes pluviométricas distribuídas em 16 municípios, conforme apresentado na Figura 1 e Tabela 1.

Foram utilizados registros históricos diários de precipitação, considerando-se como critério de escolha/seleção das estaçôes pluviométricas a existência de séries históricas com um período mínimo de 15 anos de dados e com período de tempo semelhante (séries históricas com registros relativos ao mesmo período). Quanto maior o número de anos da série histórica, melhor será a consideração do período de seca, entretanto, não existe um número de anos ideal.

As regiôes analisadas apresentam grande potencial hidrológico e distribuição uniforme das precipitaçôes ao longo do ano, com ausência de estação seca bem definida. A média da precipitação total anual apresenta valores aproximados de $1700 \mathrm{~mm}$.
Além disso, o número de dias consecutivos sem chuva nos municípios em questão (em torno de 61 dias) é bastante inferior a outros locais do Brasil, garantindo que o aproveitamento de água pluvial abastecerá o reservatório praticamente durante todo o ano, o que viabiliza a implantaçáo de sistemas de aproveitamento (Seeger et al, 2007).

A hipótese de trabalho foi utilizar as águas captadas pelo sistema de aproveitamento para satisfazer as demandas de bacias sanitárias em residências unifamiliar e multifamiliar, atividade de lavagem de veículos em postos de combustíveis e uso não potável em indústrias. Essas demandas foram obtidas a partir de padróes médios da região e conforme valores propostos por Tomaz (2003).

As Tabelas 2, 3 e 4 apresentam os parâmetros utilizados para obtenção dos consumos diários em residências unifamiliares e multifamiliar e lavagem de veículos em postos de combustíveis. A demanda industrial foi fornecida por uma empresa de bebidas da região.

Para garantir a qualidade das águas captadas e evitar a contaminação por ação dos elementos presentes na superfície de captação realizou-se o descarte dos primeiros $1,5 \mathrm{~mm}$ de chuva coletados, conforme recomendação de Tomaz (2003). Esse procedimento garantiria que as águas mais poluídas (primeiras águas) não sejam utilizadas para consumo.

Os volumes dos reservatórios de armazenamento foram adotados de acordo com os tamanhos comerciais disponíveis ou possíveis de serem obtidos por combinaçóes entre estes, conforme expresso na Tabela 5.

O volume possível de ser captado, por sua vez, foi alcançado mediante o uso da Equação 1 proposta por Azevedo Netto (2002).

$$
V=A \times P \times C
$$

Sendo:

$\mathrm{V}=$ Volume possível de ser captado (L)

$\mathrm{A}=$ Área de captação $\left(\mathrm{m}^{2}\right)$.

$\mathrm{P}=$ Precipitação diária $(\mathrm{mm})$.

$\mathrm{C}=$ Coeficiente de Escoamento Superficial (adimensional).

Quando não se dispóe de estudos precisos acerca do Coeficiente de Escoamento Superficial para uma dada área de captação analisada, ele pode ser 


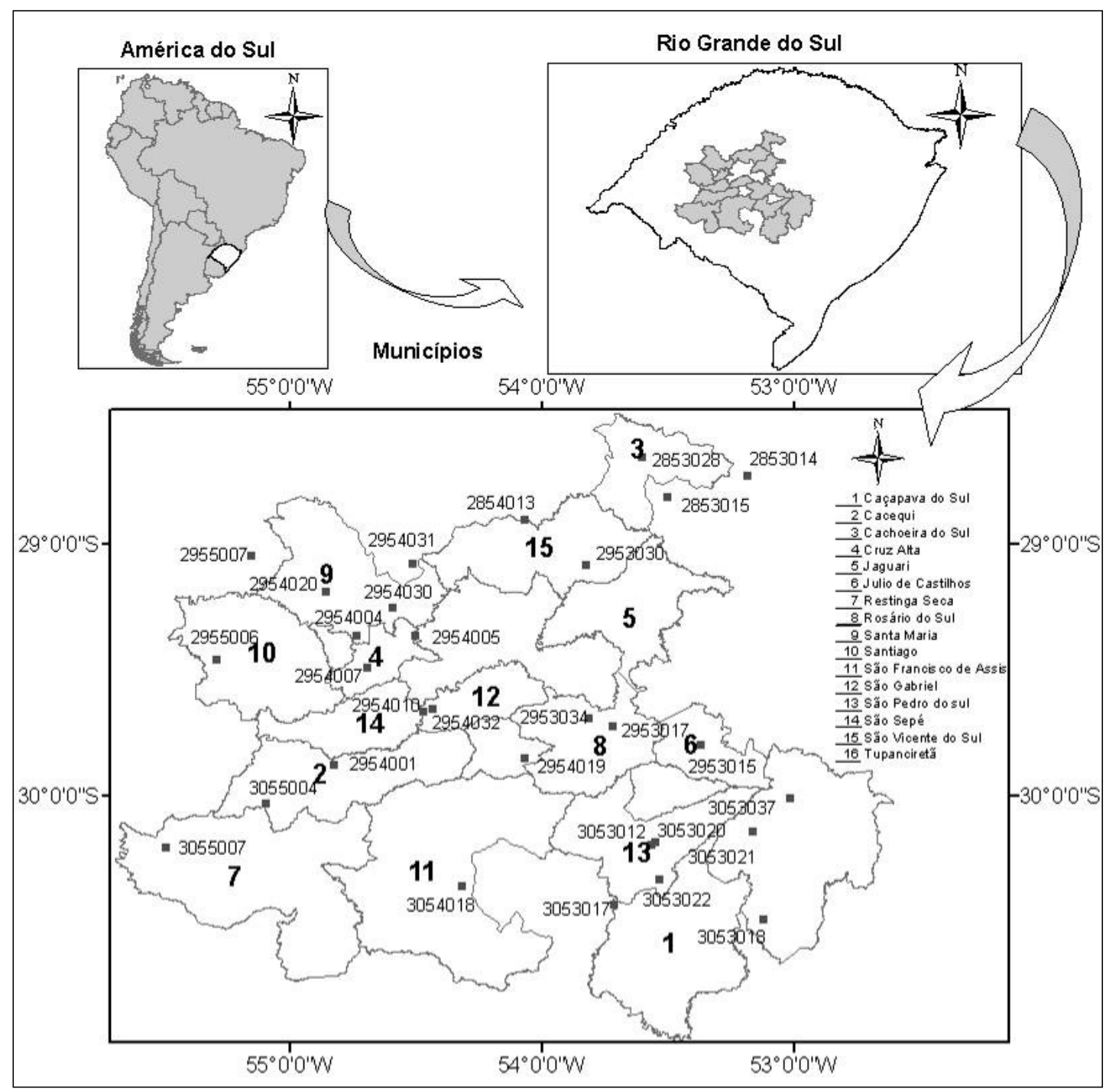

FIGURA 1. Localização dos municípios estudados no estado do Rio Grande do Sul, Brasil. 
TABELA 1

Relação dos municípios analisados no estado do Rio Grande do Sul, Brasil

\begin{tabular}{|c|c|c|c|c|c|c|}
\hline \multirow{2}{*}{$\begin{array}{l}\text { Código da } \\
\text { Estação }\end{array}$} & \multirow{2}{*}{ Nome da Estação } & \multirow{2}{*}{ Município } & \multirow{2}{*}{$\begin{array}{c}P_{\text {média anual }} \\
(\mathrm{mm})\end{array}$} & \multirow{2}{*}{$\begin{array}{l}\text { Período } \\
\text { de dados } \\
\text { (anos) }\end{array}$} & \multicolumn{2}{|c|}{ Período } \\
\hline & & & & & Início & Fim \\
\hline 02853014 & Santa Clara do Ingai & Cruz Alta & 1638,85 & 61 & $1 / 9 / 1944$ & $1 / 12 / 2005$ \\
\hline 02853015 & Três Capões & Cruz Alta & 1637,41 & 19 & $1 / 1 / 1961$ & $31 / 10 / 1980$ \\
\hline 02853028 & Anderson Clayton & Cruz Alta & 1957,20 & 23 & $1 / 4 / 1978$ & $31 / 12 / 2001$ \\
\hline 02854013 & São Bernardo & Tupanciretã & 2117,63 & 22 & $22 / 1 / 1983$ & $31 / 12 / 2005$ \\
\hline 02953015 & Restinga Seca & Restinga Seca & 1565,94 & 26 & $27 / 2 / 1951$ & $18 / 8 / 1977$ \\
\hline 02953017 & Santa Maria & Santa Maria & 1717,81 & 27 & $1 / 1 / 1939$ & $31 / 12 / 1970$ \\
\hline 02953030 & Tupanciretã & Tupanciretã & 1792,44 & 25 & $1 / 7 / 1976$ & $31 / 12 / 2001$ \\
\hline 02953034 & Santa Maria - IPAGRO & Santa Maria & 1499,91 & 33 & $1 / 1 / 1963$ & $31 / 12 / 1996$ \\
\hline 02953037 & Passo São Lourenço & Cachoeira do Sul & 1696,56 & 19 & $1 / 5 / 1986$ & $31 / 12 / 2005$ \\
\hline 02954001 & Cacequi & Cacequi & 1520,20 & 62 & 9/4/1943 & $31 / 12 / 2005$ \\
\hline 02954004 & Ernesto Alves & Jaguari & 1788,32 & 46 & $17 / 7 / 1959$ & $31 / 12 / 2005$ \\
\hline 02954005 & Furnas do Segredo & Jaguari & 1834,67 & 39 & $8 / 8 / 1966$ & $31 / 12 / 2005$ \\
\hline 02954007 & Jaguari & Jaguari & 1770,65 & 48 & $1 / 10 / 1957$ & $31 / 12 / 2005$ \\
\hline 02954010 & Ponte Toropi & São Vicente do Sul & 1462,28 & 26 & $20 / 9 / 1957$ & $31 / 12 / 1983$ \\
\hline 02954019 & Quevedos & Julio de Castilhos & 1772,63 & 29 & $16 / 5 / 1976$ & $31 / 1 / 2005$ \\
\hline 02954020 & Santiago & Santiago & 1934,61 & 29 & $1 / 8 / 1976$ & $31 / 12 / 2005$ \\
\hline 02954030 & Florida & Santiago & 1927,05 & 22 & $21 / 1 / 1983$ & $31 / 12 / 2005$ \\
\hline 02954031 & Esquina dos Lima & Santiago & 2005,22 & 18 & $22 / 1 / 1983$ & $31 / 12 / 2002$ \\
\hline 02954032 & Ponte Toropi II & São Pedro do Sul & 1749,71 & 21 & $1 / 5 / 1984$ & $31 / 12 / 2005$ \\
\hline 02955006 & Ponte da Miracatu & São Francisco de Assis & 1694,91 & 36 & $23 / 9 / 1969$ & $31 / 12 / 2005$ \\
\hline 02955007 & Unistalda & Santiago & 1883,48 & 36 & 13/9/1969 & $31 / 12 / 2005$ \\
\hline 03053012 & São Sepé & São Sepé & 1386,77 & 41 & $28 / 4 / 1943$ & $31 / 12 / 1984$ \\
\hline 03053017 & Passo dos Freires & São Sepé & 1619,15 & 24 & $28 / 5 / 1981$ & $31 / 12 / 2005$ \\
\hline 03053018 & Irapuazinho & Cachoeira do Sul & 1616,30 & 22 & $26 / 1 / 1983$ & $31 / 12 / 2005$ \\
\hline 03053020 & São Sepé- Montante & São Sepé & 1610,82 & 21 & $1 / 10 / 1984$ & $31 / 12 / 2005$ \\
\hline 03053021 & Barro Vermelho & Cachoeira do Sul & 1636,51 & 19 & $29 / 4 / 1986$ & $31 / 12 / 2005$ \\
\hline 03053022 & Caçapava do Sul & Caçapava do Sul & 1775,13 & 19 & $1 / 4 / 1986$ & $31 / 12 / 2005$ \\
\hline 03054018 & Ponte São Gabriel & São Gabriel & 1575,74 & 20 & $1 / 7 / 1985$ & $31 / 12 / 2005$ \\
\hline 03055004 & Saica & Cacequi & 1601,69 & 29 & $1 / 10 / 1976$ & $31 / 12 / 2005$ \\
\hline 03055007 & São carlos & Rosário do Sul & 1613,66 & 19 & $24 / 4 / 1986$ & $31 / 12 / 2005$ \\
\hline
\end{tabular}


TABELA 2

Parâmetros de referência para cálculo da demanda em residência unifamiliar

\begin{tabular}{|l|l|}
\hline \multicolumn{2}{|c|}{ Residência unifamiliar - bacia sanitária } \\
\hline Número de habitantes na residência* & 5 hab \\
\hline Consumo na bacia sanitária** & $12 \mathrm{~L} /$ descarga \\
\hline Número de utilização da bacia sanitária** & descargas/hab/dia \\
\hline
\end{tabular}

${ }^{*}$ Padrões médios da região

${ }^{* *}$ Valores dentro da faixa de referência proposta por Tomaz (2003)

TABELA 3

Parâmetros de referência para cálculo da demanda em residência multifamiliar

\begin{tabular}{|l|l|}
\hline \multicolumn{2}{|c|}{ Residência multifamiliar - bacia sanitária } \\
\hline Número de andares no edifício* $^{*}$ & 4 andares \\
\hline Número de apartamentos por andar* & 4 apartamentos/andar \\
\hline Número de habitantes na residência* $^{*}$ & 4 hab/apartamento \\
\hline Consumo na bacia sanitária** & 12 L/descarga \\
\hline Número de utilização da bacia sanitária** & 6 descargas/hab/dia \\
\hline
\end{tabular}

* Padrões médios da região

** Valores dentro da faixa de referência proposta por Tomaz (2003)

TABELA 4

Parâmetros de referência para cálculo da demanda em postos de combustíveis

\begin{tabular}{|l|l|}
\hline \multicolumn{2}{|c|}{ Posto de combustível - lavagem de veículos } \\
\hline Número de veículos lavados por dia* & 25 veículos/dia \\
\hline Consumo de água na lavagem ${ }^{* *}$ & $150 \mathrm{~L} /$ veículo \\
\hline
\end{tabular}

* Padrões médios da região

** Valores dentro da faixa de referência proposta por Tomaz (2003)

TABELA 5

Volumes comerciais utilizados para reservatório de armazenamento

\begin{tabular}{|l|l|}
\hline \multicolumn{1}{|c|}{ Uso } & \multicolumn{1}{c|}{ Volume do reservatório (L) } \\
\hline Residência Unifamiliar & $500,1000,2000,3000,5000,7000$ e 10000 \\
\hline Residência Multifamiliar & $7000,10000,15000,20000,25000$ e 30000 \\
\hline Postos de Combustíveis & $10000,15000,20000,30000$ e 40000 \\
\hline Indústria de Cerveja & $100000,200000,400000,600000$ e 800000 \\
\hline
\end{tabular}


adotado a partir de valores teóricos pré-estabelecidos em literatura. De acordo com Tomaz (2003), o valor estimado de 0,8 é considerado adequado para esse propósito sendo, portanto adotado nesse trabalho.

As áreas de captação foram variadas dentro de limites aceitáveis construtivamente, permitindo, dessa forma, analisar a influência dessas sobre o sistema de aproveitamento de água da chuva. $\mathrm{Na}$ Tabela 6 são apresentadas as áreas de captação utilizadas na simulação para cada tipo de demanda.

Já a análise de simulação do reservatório foi baseada na equação da continuidade, conforme Equação 2:

$$
V_{t}=V_{t-1}+V-D
$$

Sendo:

$V_{t}=$ Volume de água no reservatório no tempo $\mathrm{t}(\mathrm{L})$. $V_{t-1}=$ Volume de água no reservatório no tempo $\mathrm{t}-1$ (L).

$\mathrm{V}=$ Volume possível de ser captado (L).

$\mathrm{D}=$ Volume diário demandado $(\mathrm{L})$.

Essa simulação foi executada em planilha eletrônica do Excel', da Microsoft, utilizando equação lógica, que considerou as hipóteses do reservatório estar cheio, vazio ou parcialmente cheio. Para efeitos de cálculo, neste estudo, o reservatório de armazenamento foi considerado inicialmente cheio.

TABELA 6

\section{Volumes comerciais utilizados para reservatório de armazenamento}

\begin{tabular}{|l|l|}
\hline \multicolumn{1}{|c|}{ Uso } & \multicolumn{1}{c|}{ Áreas de captação $\mathbf{( m}^{\mathbf{2}} \mathbf{)}$} \\
\hline Residência Unifamiliar & $70,100,150,200$ e 300 \\
\hline Residência Multifamiliar & $300,500,700,1000$ e 1500 \\
\hline Postos de Combustíveis & $500,1000,1500$ e 2000 \\
\hline Indústria de Cerveja & $5000,7000,9000$ e 10000 \\
\hline
\end{tabular}

O básico da análise de simulaçáo do reservatório é que ele constitui-se um método por tentativas e erros. Supóe-se conhecido o volume do reservatório, bem como, a demanda. Nesta situação, McMahon (1993) sugere que duas hipóteses básicas devem ser satisfeitas: reservatório cheio no início da contagem do tempo e os dados históricos serem representativos para as condiçóes futuras. Além disso, o método considera que os problemas sazonais e períodos críticos de seca são ponderados na análise da série histórica.

A partir dessa análise foi possível identificar os dias falhos consecutivos, ou seja, o maior período em que o sistema não atendeu a demanda e houve a necessidade de suprimento externo, bem como, os dias falhos totais, obtidos pelo somatório de todos os dias falhos ao longo das séries analisadas.

A probabilidade de falha é a relação entre o número de dias que o reservatório náo atendeu a demanda (dias falhos totais) e o número total de dias da série histórica analisada e pode ser expresso pela Equação 3.

$P_{F}=\frac{D f t}{T d} \cdot 100$

Sendo:

$P_{F}=$ Probabilidade de falha do sistema (\%).

$D f t=$ Dias falhos totais (dias).

$\mathrm{Td}=$ Número total de dias da série (dias).

A eficiência por sua vez, representa a proporção do tempo em que o reservatório atende a demanda. Para McMahon (1993) ela pode ser entendida como o complemento da falha sendo, portanto expressa pela Equação 4.

$$
E=100-P_{F}
$$

Sendo:

$E$ = Eficiência do sistema (\%).

$P_{F}=$ Probabilidade de falha (\%).

Foram realizadas simulaçôes com diferentes volumes para um mesmo valor de área de captaçáo. A seguir alterou-se a área para os mesmos valores de volumes utilizados anteriormente, obtendo-se graficamente a relação volume x eficiência do sistema de aproveitamento para cada área e demanda. Esse processo foi realizado para as diferentes estaçóes pluviométricas estudadas.

Para cada demanda procedeu-se então, os cálculos das eficiências médias do sistema de aproveitamento pluvial e dos desvios padrôes dessas eficiências em relação à média. Esse cálculo foi realizado para cada área de captaçáo determinando-se, 
para cada volume estudado, a eficiência média das 30 estações.

\section{RESULTADOS E DISCUSSÕES}

O consumo médio calculado para utilização em bacias sanitárias foi de $360 \mathrm{~L} /$ dia para residência unifamiliar e 4608 L/dia para multifamiliar. Já a demanda média obtida para o processo de lavagem de veículos foi de $3.750 \mathrm{~L} /$ dia e o consumo em indústrias foi de $50.000 \mathrm{~L} /$ dia; sendo que a análise da eficiência para cada uma dessas demandas revelou índices comportamentais semelhantes entre as estaçôes pluviométricas.

Assim, em decorrência do número de estações estudadas (30 estaçôes), da extensa análise em termos de variaçóes de área de captação e volume de armazenamento para cada uma das demandas consideradas no estudo e, particularmente, em razão da existência de semelhança na eficiência do sistema; optou-se aqui por demonstrar os resultados (por estação pluviométrica) obtidos para as simulações em residência unifamiliar.

A Tabela 7 apresenta os resultados da eficiência do sistema para cada uma das 30 estaçôes, considerando demanda em residência unifamiliar. A título de exemplificação: para a área de $100 \mathrm{~m}^{2}$ e volume de $3.000 \mathrm{~L}$ o valor da eficiência variou entre $52,87 \%$ e $68,60 \%$, ou seja, encontrou-se uma eficiência média de 61,65\% e desvio padrão de 3,61.

Percebe-se, ainda, que existe um crescimento da eficiência em funçáo do aumento do volume de armazenamento do reservatório considerando-se a área constante (observar valores entre duas linhas subsequentes de uma mesma coluna). Da mesma forma, visualiza-se um crescimento da eficiência em relação ao aumento da área de captação quando se considera o volume de armazenamento constante (observar valores da eficiência para áreas diferentes e mesmo volume do reservatório).

Já na Tabela 8 estão dispostos os valores médios da eficiência do sistema e o desvio padrão encontrados, considerando demanda em residência unifamiliar.

Os resultados demonstram um comportamento semelhante ao descrito no parágrafo anterior: a eficiência média do sistema cresce com o aumento do volume para uma área constante (observar valores entre duas linhas subsequentes em uma mesma coluna da tabela) e com o aumento da área para um volume constante (observar valores entre duas colunas subsequentes em uma mesma linha).
O desvio padrão das eficiências do sistema para as 30 estaçóes em relação à eficiência média cresce com o aumento da área para um volume constante de até $3.000 \mathrm{~L}$ e diminui para volumes entre $5.000 \mathrm{~L}$ e $10.000 \mathrm{~L}$. Considerando-se área constante e volume variável, o desvio padráo cresce com o aumento do volume para áreas de $70 \mathrm{~m}^{2} \mathrm{e}$ $100 \mathrm{~m}^{2}$, já para áreas de $150 \mathrm{~m}^{2}$ a $200 \mathrm{~m}^{2}$ ocorre um crescimento para volumes até $3.000 \mathrm{~L}$ e um decréscimo para volumes entre $5.000 \mathrm{~L}$ e 10.000 ; enquanto que para área de $300 \mathrm{~m}^{2}$ o desvio aumenta até o volume de $2.000 \mathrm{~L}$ e diminui entre $3.000 \mathrm{~L}$ e $10.000 \mathrm{~L}$.

Já a variação da eficiência média (diferença entre um dado valor de eficiência e seu valor subsequente) diminui com o aumento da área para um volume constante, oscilando em torno de $1,16 \%$ a $16,65 \%$ (observar valores entre colunas subsequentes em uma mesma linha da tabela).

Entretanto, quando se analisa a diferença entre as eficiências médias para área constante e diferentes volumes de armazenamento (observar valores entre linhas subsequentes em uma mesma coluna da tabela) não é possível estipular um padrão nessa variação, pois inicialmente há um crescimento da diferença entre as eficiências médias para após ocorrer uma diminuição.

$\mathrm{Na}$ Figura 2 visualiza-se um crescimento logaritmo da eficiência média em função do aumento dos valores da área de captação e volume de armazenamento do reservatório. Volumes de $500 \mathrm{~L}$ implicaram índices de eficiência médias superiores a 25,99\%, independente da área considerada. Já reservatórios de $3.000 \mathrm{~L}$ alcançaram resultados superiores a 51,88\%, atingindo-se $97,38 \%$ de eficiência média quando da utilização de $10.000 \mathrm{~L}$ e área de captação de $300 \mathrm{~m}^{2}$.

Destaca-se, entretanto, que o crescimento da eficiência média em função do aumento do volume torna-se menos significativo para volumes superiores a 7.000 L com área de captaçáo constante, tendendo a estabilidade (observar que a curva gráfica torna-se mais amena a partir desse volume). Em contrapartida, mantendo-se o volume constante, percebe-se que a variação da eficiência média é mais expressiva para uma elevação de área entre $70 \mathrm{~m}^{2} \mathrm{e}$ $150 \mathrm{~m}^{2}$ e menos representativo para valores acima deste último.

A Tabela 9 mostra as eficiências médias e os desvios padróes encontrados para a demanda em residência multifamiliar $(4608 \mathrm{~L} / \mathrm{dia})$. 


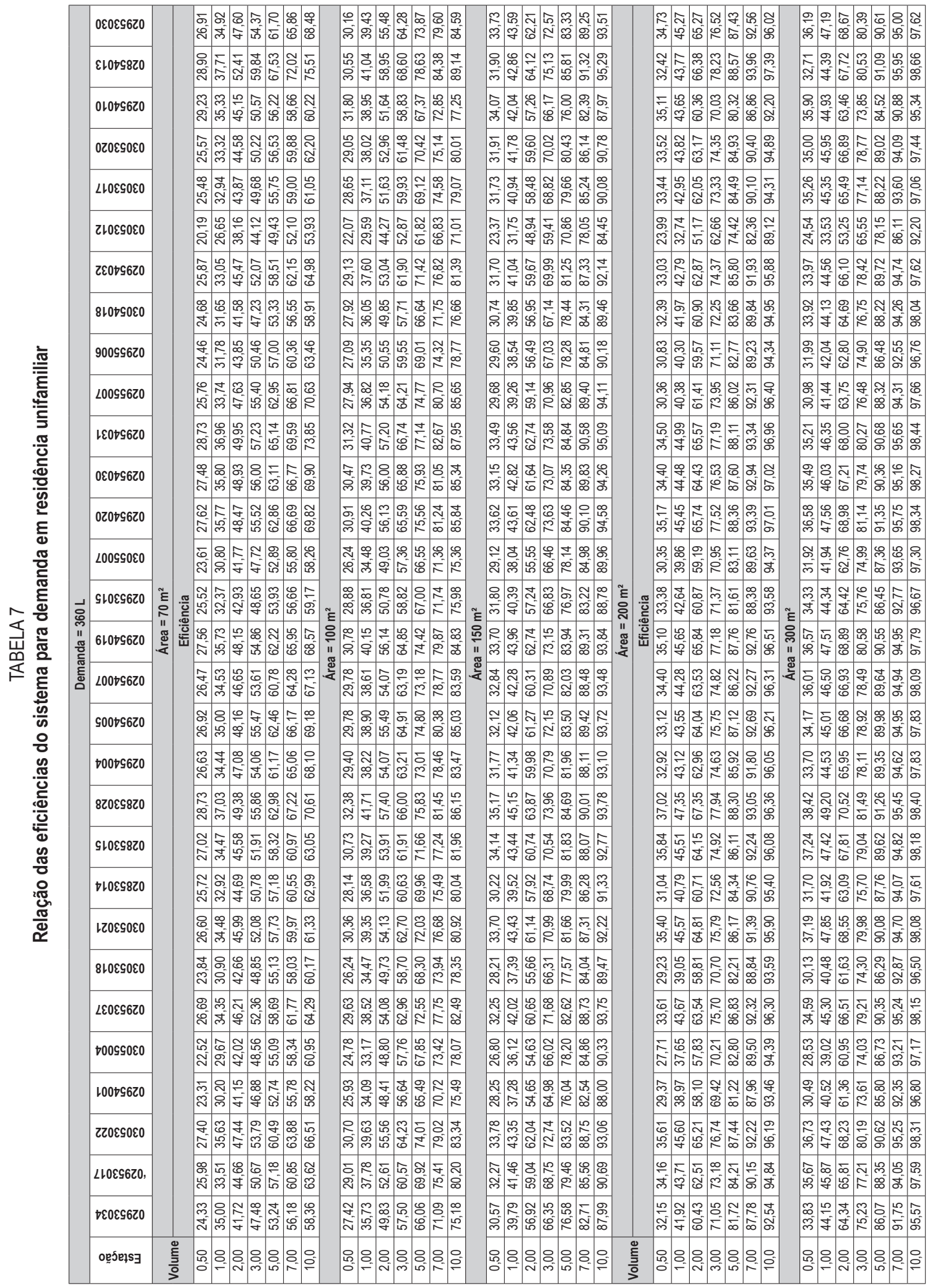




\section{Demanda 360 L/dia}

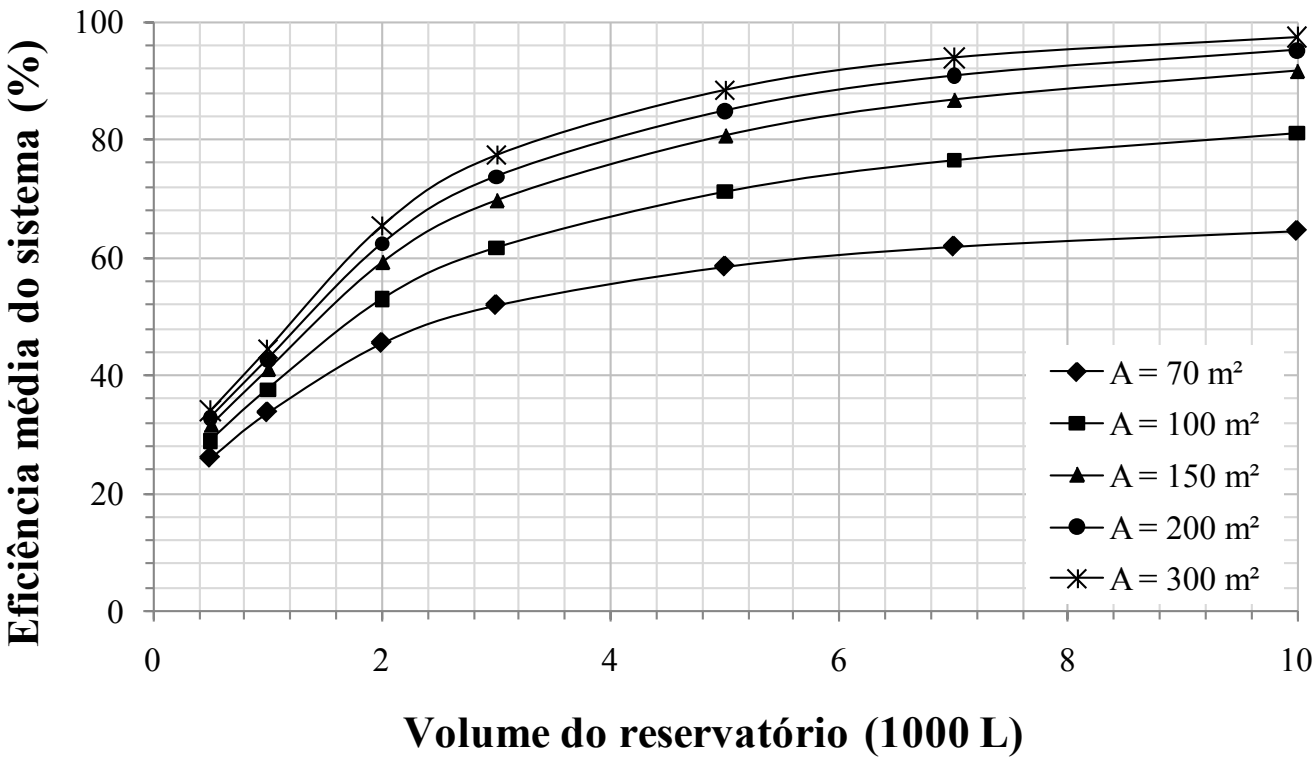

FIGURA 2. Volume x Eficiência média do sistema de aproveitamento para uma residência unifamiliar.

TABELA 8

Eficiências médias para demanda em residência unifamiliar

\begin{tabular}{|c|c|c|c|c|c|c|c|c|c|c|}
\hline \multicolumn{11}{|c|}{ Demanda diária de 360 (I) } \\
\hline \multirow[b]{2}{*}{$\begin{array}{l}\text { Vo- } \\
\text { lume } \\
\left(\mathrm{m}^{3}\right)\end{array}$} & Área $\left(\mathrm{m}^{2}\right)$ & 70 & Área $\left(\mathrm{m}^{2}\right)$ & 100 & Área $\left(\mathrm{m}^{2}\right)$ & 150 & Área $\left(m^{2}\right)$ & 200 & Área $\left(m^{2}\right)$ & 300 \\
\hline & $\begin{array}{c}\text { Eficiência } \\
\text { média do } \\
\text { sistema } \\
(\%)\end{array}$ & $\begin{array}{c}\text { Desvio } \\
\text { pa- } \\
\text { drão }\end{array}$ & $\begin{array}{l}\text { Eficiência } \\
\text { média do } \\
\text { sistema } \\
(\%)\end{array}$ & $\begin{array}{l}\text { Des- } \\
\text { vio } \\
\text { pa- } \\
\text { drão }\end{array}$ & $\begin{array}{l}\text { Eficiência } \\
\text { média do } \\
\text { sistema } \\
(\%)\end{array}$ & $\begin{array}{l}\text { Des- } \\
\text { vio } \\
\text { pa- } \\
\text { drão }\end{array}$ & $\begin{array}{c}\text { Eficiência } \\
\text { média do } \\
\text { sistema (\%) }\end{array}$ & $\begin{array}{l}\text { Des- } \\
\text { vio } \\
\text { pa- } \\
\text { drão }\end{array}$ & $\begin{array}{l}\text { Eficiência } \\
\text { média do } \\
\text { sistema (\%) }\end{array}$ & $\begin{array}{l}\text { Desvio } \\
\text { padrão }\end{array}$ \\
\hline 0,50 & 25,99 & 2,02 & 28,91 & 2,25 & 31,51 & 2,54 & 32,81 & 2,76 & 33,97 & 2,96 \\
\hline 1,00 & 33,69 & 2,43 & 37,61 & 2,66 & 40,96 & 2,85 & 42,72 & 3,01 & 44,42 & 3,23 \\
\hline 2,00 & 45,46 & 3,14 & 52,93 & 3,24 & 59,14 & 3,32 & 62,29 & 3,33 & 65,38 & 3,40 \\
\hline 3,00 & 51,88 & 3,61 & 61,65 & 3,61 & 69,63 & 3,46 & 73,70 & 3,35 & 77,36 & 3,28 \\
\hline 5,00 & 58,41 & 4,27 & 71,14 & 4,02 & 80,64 & 3,43 & 84,85 & 3,10 & 88,43 & 2,70 \\
\hline 7,00 & 61,80 & 4,74 & 76,49 & 4,19 & 86,70 & 3,10 & 90,77 & 2,48 & 93,92 & 1,92 \\
\hline 10,00 & 64,45 & 5,22 & 81,10 & 4,36 & 91,61 & 2,61 & 95,15 & 1,77 & 97,38 & 1,26 \\
\hline
\end{tabular}


Sari, V.; Seeger, L. M. K.; Paiva, E. M. C. D. de; Rosa, A. L. D. da ミ Eficiência de sistemas de aproveitamento de águas pluviais...

TABELA 9

Eficiências médias para demanda em residência multifamiliar

\begin{tabular}{|c|c|c|c|c|c|c|c|c|c|c|}
\hline \multicolumn{10}{|c|}{ Demanda diária de $\mathbf{4 6 0 8}(\mathbf{L})$} \\
\hline & Área $\left(\mathbf{m}^{2}\right)$ & $\mathbf{3 0 0}$ & Área $\left(\mathbf{m}^{2}\right)$ & $\mathbf{5 0 0}$ & Área $\left(\mathbf{m}^{2}\right)$ & $\mathbf{7 0 0}$ & Área $\left(\mathbf{m}^{2}\right)$ & $\mathbf{1 . 0 0 0}$ & Área $\left(\mathbf{m}^{2}\right)$ & $\mathbf{1 . 5 0 0}$ \\
\cline { 2 - 12 } $\begin{array}{c}\text { Volume } \\
\left(\mathbf{m}^{3}\right)\end{array}$ & $\begin{array}{c}\text { Eficiência } \\
\text { Média do } \\
\text { sistema (\%) }\end{array}$ & $\begin{array}{c}\text { Des- } \\
\text { vio } \\
\text { pa- } \\
\text { drão }\end{array}$ & $\begin{array}{c}\text { Eficiência } \\
\text { Média do } \\
\text { sistema }(\%)\end{array}$ & $\begin{array}{c}\text { Des- } \\
\text { vio } \\
\text { pa-- } \\
\text { drão }\end{array}$ & $\begin{array}{c}\text { Eficiência } \\
\text { Média do } \\
\text { sistema }(\%)\end{array}$ & $\begin{array}{c}\text { Des- } \\
\text { vio } \\
\text { pa- } \\
\text { drão }\end{array}$ & $\begin{array}{c}\text { Eficiência } \\
\text { Média do } \\
\text { sistema }(\%)\end{array}$ & $\begin{array}{c}\text { Des- } \\
\text { vio } \\
\text { pa-- } \\
\text { drão }\end{array}$ & $\begin{array}{c}\text { Eficiência } \\
\text { Média do } \\
\text { sistema }(\%)\end{array}$ & $\begin{array}{c}\text { Des- } \\
\text { vio } \\
\text { pa- } \\
\text { drão }\end{array}$ \\
\hline 7,00 & 12,73 & 1,40 & 19,53 & 1,78 & 23,55 & 1,91 & 27,01 & 2,10 & 30,12 & 2,39 \\
\hline 10,00 & 14,21 & 1,64 & 23,13 & 2,17 & 28,62 & 2,37 & 33,51 & 2,57 & 37,87 & 2,84 \\
\hline 15,00 & 15,21 & 1,80 & 26,01 & 2,44 & 32,98 & 2,67 & 39,27 & 2,82 & 44,84 & 3,01 \\
\hline 20,00 & 15,77 & 1,93 & 27,98 & 2,64 & 36,23 & 2,90 & 43,82 & 3,08 & 50,48 & 3,19 \\
\hline 25,00 & 16,08 & 2,01 & 29,38 & 2,82 & 38,77 & 3,11 & 47,52 & 3,28 & 55,16 & 3,33 \\
\hline 30,00 & 16,26 & 2,07 & 30,40 & 3,01 & 40,78 & 3,30 & 50,59 & 3,44 & 59,16 & 3,45 \\
\hline
\end{tabular}

Evidencia-se a existência de um crescimento da eficiência média do sistema em função do aumento do volume para uma área constante. Da mesma forma, um aumento da área de captação para um volume constante gera elevaçáo dos índices de eficiência média.

Já o desvio padrão cresce com o aumento da área para um volume constante de até $2.000 \mathrm{~L}$ e diminui para volumes entre 3.000 L e 10.000 L. Quando se considera área constante e volume variável, o desvio cresce com o aumento do volume para áreas de $70 \mathrm{~m}^{2}$ e $100 \mathrm{~m}^{2}$, já para áreas de $150 \mathrm{~m}^{2}$ e $200 \mathrm{~m}^{2}$ ocorre um crescimento para volumes até $3.000 \mathrm{~L}$ e um decréscimo para volumes entre $5.000 \mathrm{~L}$ e $10.000 \mathrm{~L}$; enquanto que para área de $300 \mathrm{~m}^{2}$ o desvio aumenta até o volume de $2.000 \mathrm{~L}$ e diminui entre $3.000 \mathrm{~L}$ e $10.000 \mathrm{~L}$.

É possível observar, ainda, que a variação da eficiência média diminui com o aumento da área para um volume constante, bem como, para o aumento do volume a uma dada área constante. Essa variação oscila entre $0,19 \%$ a $6,50 \%$ quando o volume aumenta e a área de captação permanece constante, alcançando valores mais expressivos (entre 3,12\% a $14,14 \%$ ) quando a área de captação aumenta e o volume de armazenamento permanece constante.

A Figura 3 traz a relação volume $x$ eficiência média do sistema de aproveitamento para uma residência multifamiliar.

O gráfico demonstra um crescimento pouco significativo da eficiência média em função do acréscimo nos valores da área de captação (quando o volume é constante) ou do aumento do volume de armazenamento do reservatório (quando a área é constante), tendendo a linearidade, sobretudo para áreas pequenas $\left(70 \mathrm{~m}^{2}\right.$ e $\left.100 \mathrm{~m}^{2}\right)$.

É interessante destacar que a estabilização do crescimento da eficiência média em função do aumento do volume do reservatório ocorre mais rapidamente para as menores áreas quando comparadas as maiores, ou seja, para estas últimas a estabilização acontece em volumes mais elevados. Este fato pode estar atrelado à existência de uma relaçáo ideal entre os diferentes componentes do sistema de aproveitamento, ou seja, existe um sistema ideal para uma dada eficiência pretendida e esse sistema terá uma área de captação e volume de armazenamento específico para cada demanda. Ou seja, deve haver um ponto em que o aumento do volume do reservatório não surte efeito sobre a eficiência quando o sistema possui pequena área de captação, uma vez que, não existe área suficiente para abastecê-lo completamente e, portanto a eficiência resulta muito parecida com aquela que seria obtida para menores volumes de armazenamento.

Essa análise permite concluir que em pequenas áreas de captação o controle da oferta é dado pela área enquanto que, para grandes áreas esse controle está relacionado ao tamanho do reservatório.

Para volumes de armazenamento de $7.000 \mathrm{~L}$ obteve-se eficiência superior a $12,73 \%$, qualquer que fosse a área considerada. Já em reservatórios de $15.000 \mathrm{~L}$ os resultados são superiores a $15,21 \%$, 


\section{Demanda 4608 L/dia}

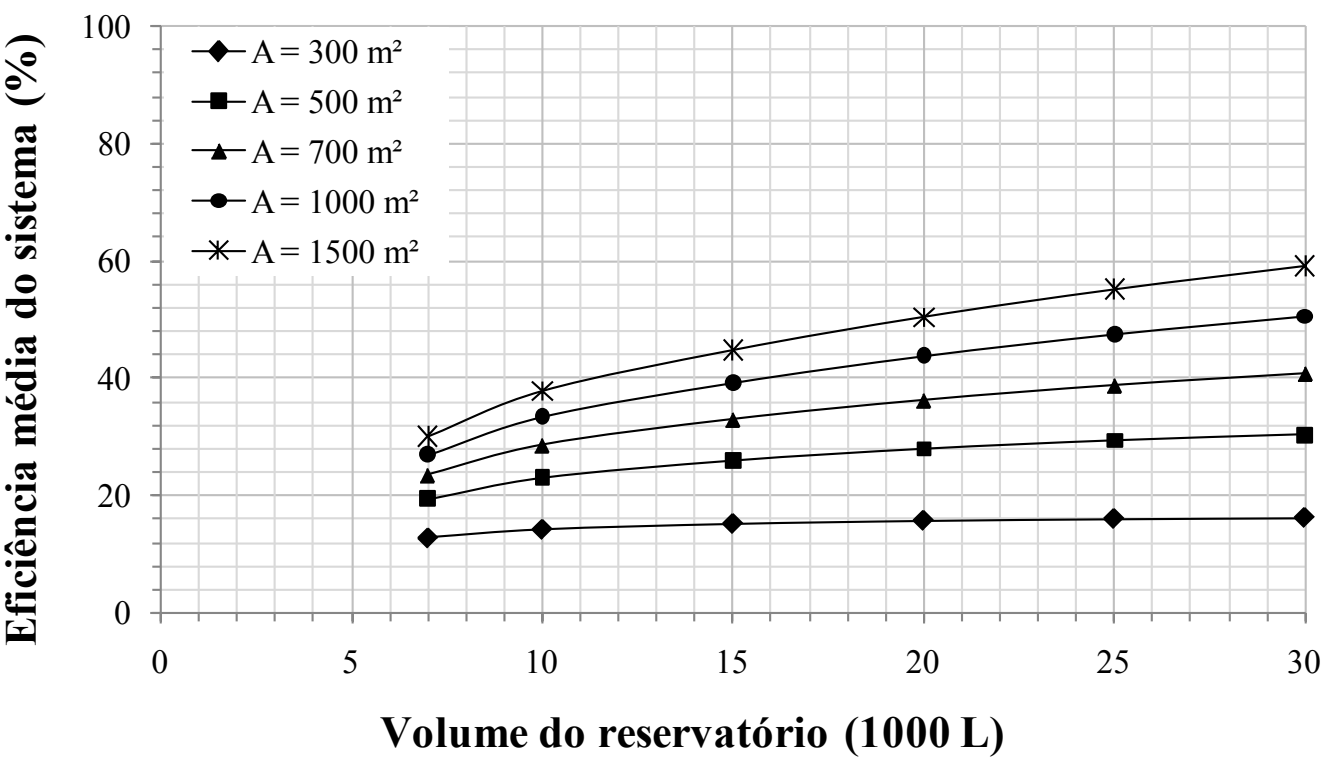

FIGURA 3. Volume x Eficiência média do sistema de aproveitamento para uma residência multifamiliar.

alcançando-se 59,16\% quando da utilização de $30.000 \mathrm{~L}$ e área de captação de $1.500 \mathrm{~m}^{2}$. Os baixos índices de eficiência média podem estar relacionados ao aumento da demanda diária.

A Tabela 10 apresenta as eficiências médias e os desvios padrôes encontrados para a demanda em postos de combustíveis (3.750 L/dia).

Percebe-se que a eficiência média cresce com o aumento da área para um volume constante e também para a elevação do volume a uma área constante. Já o desvio padrão cresce para um aumento do volume com área constante, com exceçấo do volume de $40.000 \mathrm{~L}$ e área de $2.000 \mathrm{~m}^{2}$. No que se refere ao aumento da área a volume constante, ocorre um crescimento do desvio padrão à exceçáo do volume de $40.000 \mathrm{~L}$ para área de $1500 \mathrm{~m}^{2}$ e volumes de 30.000 L e $40.000 \mathrm{~L}$ para área de $2.000 \mathrm{~m}^{2}$.

Visualiza-se ainda, uma significativa variação da eficiência média em função do crescimento da área de captação para volume de armazenamento constante (entre $1,80 \%$ a $24,63 \%$ ). Entretanto, a variação da eficiência média em função do aumento do volume para área constante não segue um padrão comportamental específico, alternando aumento e diminuição dessa variaçáo, conforme aumento do volume do reservatório.

A Figura 4 traz a relação volume x eficiência média do sistema de aproveitamento em postos de combustíveis.

Essa análise evidencia um crescimento lento da eficiência média em função do aumento do volume de armazenamento do reservatório para uma área de captação de $500 \mathrm{~m}^{2}$ (tendência a linearização do gráfico) e uma elevaçáo mais significativa para as demais áreas consideradas. A menor eficiência média encontrada para o volume de $10.000 \mathrm{~L}$ foi superior a $27,54 \%$. Já em reservatórios de $20.000 \mathrm{~L}$ atingiu-se valor superior a $35,22 \%$, alcançando-se $78,73 \%$ quando da utilizaçáo de 40.000 L e área de captação de $2.000 \mathrm{~m}^{2}$.

Ressalta-se que o crescimento da eficiência para um mesmo volume é mais expressivo em função de uma variação da área de capitação entre 500 e 1.000 $\mathrm{m}^{2}$ do que entre $1.000 \mathrm{~m}^{2}$ e $2.000 \mathrm{~m}^{2}$. 
TABELA 10

Eficiências médias para a demanda em postos de combustíveis

\begin{tabular}{|c|c|c|c|c|c|c|c|c|}
\hline \multicolumn{10}{|c|}{ Demanda diária de $\mathbf{3 7 5 0}(\mathbf{L})$} \\
\hline \multirow{2}{*}{ Volume $\left(\mathbf{m}^{3}\right)$} & Área $\left(\mathbf{m}^{2}\right)$ & $\mathbf{5 0 0}$ & Área $\left(\mathbf{m}^{2}\right)$ & 1.000 & Área $\left(\mathbf{m}^{2}\right)$ & 1.500 & Área $\left(\mathbf{m}^{2}\right)$ & $\mathbf{2 . 0 0 0}$ \\
\cline { 2 - 9 } & $\begin{array}{c}\text { Eficiência } \\
\text { Média do } \\
\text { sistema (\%) }\end{array}$ & $\begin{array}{c}\text { Desvio } \\
\text { padrão }\end{array}$ & $\begin{array}{c}\text { Eficiência } \\
\text { Média do } \\
\text { sistema (\%) }\end{array}$ & $\begin{array}{c}\text { Desvio } \\
\text { padrão }\end{array}$ & $\begin{array}{c}\text { Eficiência } \\
\text { Média do } \\
\text { sistema (\%) }\end{array}$ & $\begin{array}{c}\text { Desvio } \\
\text { padrão }\end{array}$ & $\begin{array}{c}\text { Eficiência } \\
\text { Média do } \\
\text { sistema (\%) }\end{array}$ & $\begin{array}{c}\text { Desvio } \\
\text { padrão }\end{array}$ \\
\hline 10,00 & 27,54 & 2,36 & 37,06 & 2,73 & 40,51 & 2,90 & 42,31 & 3,07 \\
\hline 15,00 & 31,45 & 2,67 & 43,55 & 3,03 & 47,99 & 3,16 & 50,34 & 3,27 \\
\hline 20,00 & 35,22 & 3,04 & 51,70 & 3,34 & 58,21 & 3,39 & 61,65 & 3,43 \\
\hline 30,00 & 38,47 & 3,45 & 58,99 & 3,68 & 66,66 & 3,59 & 70,51 & 3,50 \\
\hline 40,00 & 40,59 & 3,85 & 65,22 & 3,97 & 74,36 & 3,65 & 78,73 & 3,46 \\
\hline
\end{tabular}

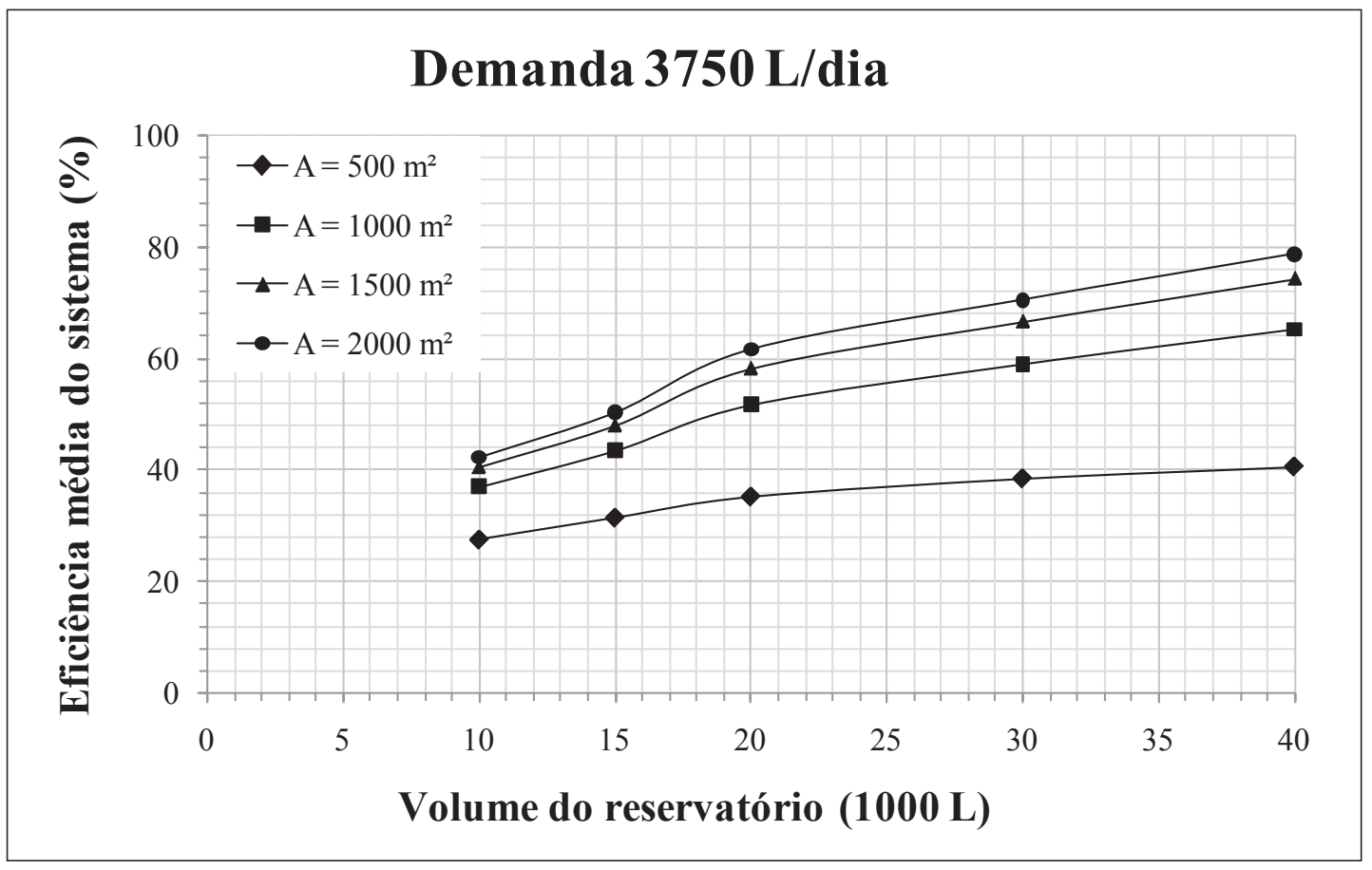

FIGURA 4. Volume x Eficiência média do sistema de aproveitamento para postos de combustíveis. 
A Tabela 11 apresenta as eficiências médias e os desvios padróes encontrados para a demanda em indústria $(50.000 \mathrm{~L} / \mathrm{dia})$.

A análise dos resultados revela que a eficiência média do sistema cresce com o aumento da área para volume constante e também para uma elevação do volume a área constante. Entretanto, observa-se que a variação dessa eficiência diminui com o aumento da área de captação para um volume constante (entre $0,81 \%$ e $14,59 \%)$ e semelhante comportamento é verificado quando se compara a variação da eficiência média em função do aumento do volume a uma dada área constante (entre 0,37\% a 12,30\%).

Percebe-se ainda, que o desvio padrão cresce com aumento do volume para uma área constante e também para o aumento da área a um volume constante (com exceção do volume de $800.000 \mathrm{~L}$ e área de $\left.10.000 \mathrm{~m}^{2}\right)$.

A Figura 5 retrata a relação volume x eficiência média do sistema de aproveitamento em uma indústria.

A análise do gráfico demonstra um crescimento pouco significativo da eficiência em função do aumento dos valores da área de captação e volume de armazenamento do reservatório. Para volume de $100.000 \mathrm{~L}$ obteve-se valor mínimo superior a 19,18\%, qualquer que fosse a área considerada. Já para reservatórios de $400.000 \mathrm{~L}$ alcançou-se resultados superiores a $28,72 \%$, atingindo-se índice superior a $60,97 \%$ quando da utilização de 800.000 L e área de captação de $10.000 \mathrm{~m}^{2}$.

É também possível definir que a tendência à estabilidade da eficiência ocorre a partir do volume de $400.000 \mathrm{~L}$ para as áreas entre 5.000 a $7.000 \mathrm{~m}^{2}$.

Em termos gerais, o comportamento da eficiência média do sistema foi semelhante para todos os tipos de demanda, ocorrendo um crescimento para um aumento da área (a volume constante) e para uma elevação de volume (a área constante). Já a variação da eficiência decresce com o aumento da área a volume constante, ou seja, os incrementos nos índices tornam-se menos expressivo na medida em que se aumenta a área de captação sem alterar o reservatório; isso provavelmente, em razão de que não há volume suficiente para armazenar a água que poderia ser coletada. Em contrapartida, quando se aumenta o volume para uma área constante não é possível definir um padrão de comportamento para a variação da eficiência para as demandas unifamiliar e em postos de combustíveis; já para residência multifamiliar e indústria ocorre uma diminuição desses valores, provavelmente em função de que o reservatório nunca ficará completamente cheio, pois a área pode não ser suficiente para esse volume

\section{CONSIDERAÇÕES FINAIS}

A captação pluvial oferece grande contribuição à redução do déficit hídrico em termos quantitativos, destacando-se por sua simplicidade. No entanto, a difusão desses sistemas de aproveitamento depende, dentre outras coisas, da viabilidade econômica de suas implantaçóes.

Dessa forma, a metodologia proposta neste estudo oferece uma visão interligada da influência dos diferentes constituintes do sistema de aproveitamento, simulando o comportamento deste como um todo. O objetivo é torná-la um instrumento de referência e auxílio ao desenvolvimento de projetos desse gênero, permitindo que se visualize, graficamente, a eficiência a ser obtida para dada área, demanda e volume de reservatório pré-definidos. Possibilita ainda, verificar as dimensóes a serem implantadas em termos de área de captação e volume de armazenamento, conhecida a demanda, para que se atinja determinada eficiência.

É possível dizer que, teoricamente, quanto maior for a área de captação, maior será a economia no suprimento externo de água. Porém, existe uma relação entre essa economia, a área de captação e o volume do reservatório. Por exemplo, se for optado pela utilização de um volume de captação pequeno, de nada adianta prever uma área de captação grande, já que no momento de ocorrência da precipitação, a água coletada facilmente preenche esse volume e o restante será descartado, sem aproveitamento. O mesmo acontece se, para dada área de coleta, utilizar-se volumes bastante elevados. Na prática é provável que muito raramente eles atingirão sua máxima capacidade e, consequentemente, haverá um desperdício do espaço físico e dos recursos empregados para a construção/implantação do sistema de aproveitamento.

\section{AGRADECIMENTOS}

Ao CT-Hidro e ao Conselho Nacional de Desenvolvimento Científico e Tecnológico (CNPq) pelos recursos financeiros e bolsas fornecidas. Ao Departamento de Engenharia Sanitária e Ambiental da Universidade Federal de Santa Maria. 
TABELA 11

Eficiências médias para demanda em, indústrias

\begin{tabular}{|c|c|c|c|c|c|c|c|c|}
\hline \multicolumn{10}{|c|}{ Demanda diária de $\mathbf{5 0 0 0 0}(\mathbf{L})$} \\
\hline & Área $\left(\mathbf{m}^{2}\right)$ & $\mathbf{5 . 0 0 0}$ & Área $\left(\mathbf{m}^{2}\right)$ & 7.000 & Área $\left(\mathbf{m}^{2}\right)$ & $\mathbf{9 . 0 0 0}$ & Área $\left(\mathbf{m}^{2}\right)$ & 10.000 \\
\cline { 2 - 9 } Volume $\left(\mathbf{m}^{3}\right)$ & $\begin{array}{c}\text { Eficiência } \\
\text { Média do } \\
\text { sistema (\%) }\end{array}$ & $\begin{array}{c}\text { Desvio } \\
\text { padrão }\end{array}$ & $\begin{array}{c}\text { Eficiência } \\
\text { Média do } \\
\text { sistema (\%) }\end{array}$ & $\begin{array}{c}\text { Desvio } \\
\text { padrão }\end{array}$ & $\begin{array}{c}\text { Eficiência } \\
\text { Média do } \\
\text { sistema (\%) }\end{array}$ & $\begin{array}{c}\text { Desvio } \\
\text { padrão }\end{array}$ & $\begin{array}{c}\text { Eficiência } \\
\text { Média do } \\
\text { sistema }(\%)\end{array}$ & $\begin{array}{c}\text { Desvio } \\
\text { padrão }\end{array}$ \\
\hline 100,00 & 19,18 & 1,80 & 23,42 & 1,97 & 26,03 & 2,10 & 26,83 & 2,17 \\
\hline 200,00 & 24,96 & 2,43 & 32,51 & 2,71 & 37,45 & 2,85 & 39,14 & 2,88 \\
\hline 400,00 & 28,72 & 3,08 & 40,15 & 3,50 & 48,40 & 3,66 & 51,42 & 3,68 \\
\hline 600,00 & 29,79 & 3,35 & 43,26 & 4,06 & 53,53 & 4,18 & 57,50 & 4,19 \\
\hline 800,00 & 30,16 & 3,47 & 44,75 & 4,40 & 56,42 & 4,60 & 60,97 & 4,58 \\
\hline
\end{tabular}

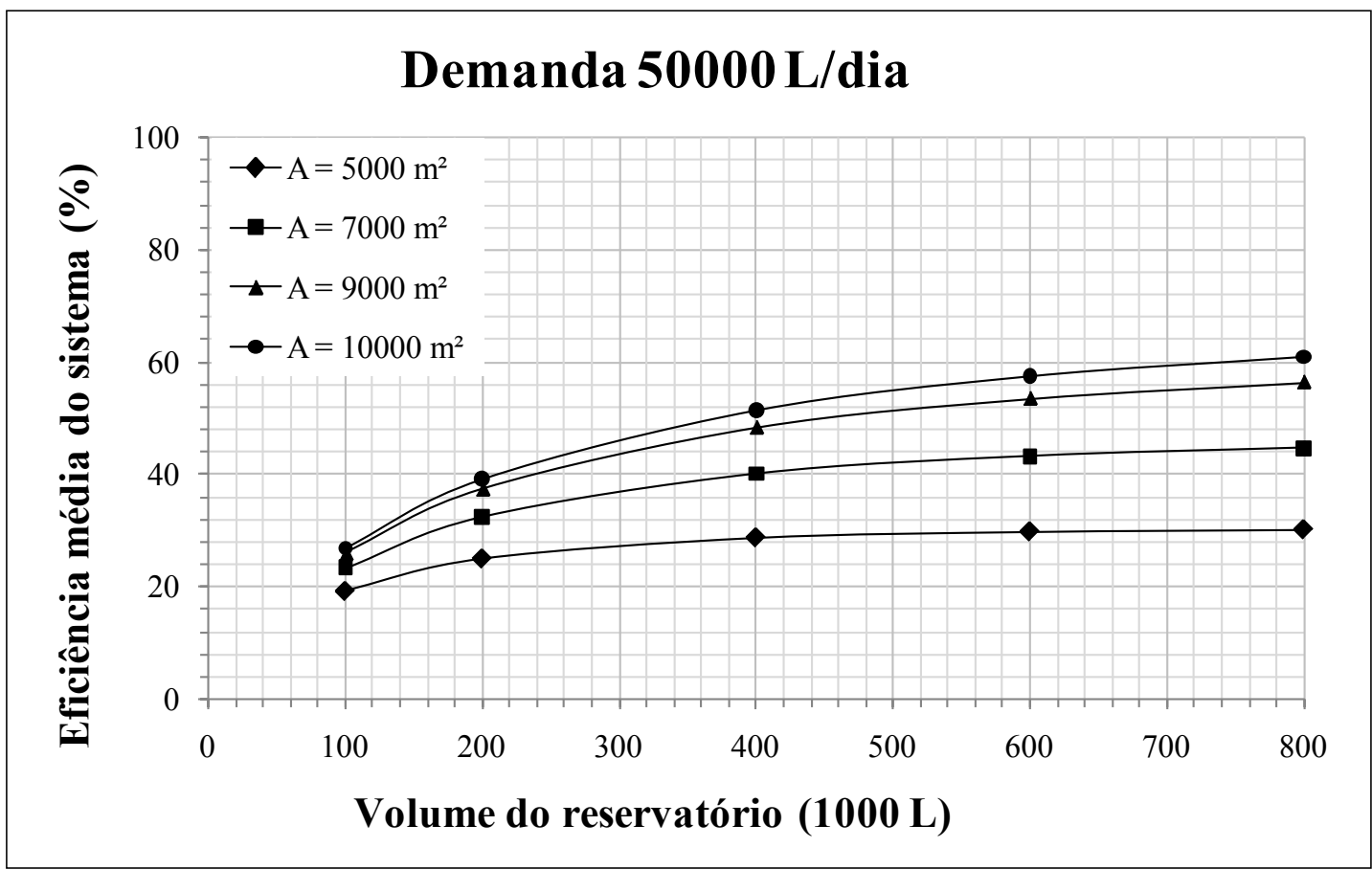

FIGURA 5. Volume x Eficiência média do sistema de aproveitamento para demanda industrial.

\section{Referências}

AGARWAL, A. et. al.TAC BACKGROUND PAPERS -Integrated Water Resources Management. Suécia, 2000, n 4, 71p. Publicado por: Global Water Partnership. Disponivel em: http://www.gwpforum.org/servlet/PSP. Acesso em: 10 jun. 2009.

AGÊNCIA NACIONAL DE ÁGUAS (ANA), FEDERAÇÃO DAS INDÚSTRIAS DO ESTADO DE SÃO PAULO (FIESP) e SINDICATO DA INDÚSTRIADA CONSTRUÇÃO CIVIL DO ESTADO DE SÃO PAULO (SINDUSCON-SP). Conservação e Reúso de água em Edificações. São Paulo: Prol Editora Gráfica. 2005. 
ANNECCHINI, K.P.V. et al. IV-010 - Dimensionamento de Reservatório de Água de Chuva para Uso Não Potável em Edificações na Cidade de Vitória (ES). VIII SIMPÓSIO ÍTALO BRASILEIRO DE ENGENHARIA SANITÁRIAE EMBIENTAL. 17 A22 de setembro de 2006. Fortaleza, CE. Associação Brasileira de Engenharia Sanitária e Ambiental, ABES.

AZEVEDO NETTO, J.M. et al. Manual de Hidráulica. São Paulo: $8^{\mathrm{a}}$ ed., 2002. 669 pg. Ed: Edgard Blucher.

BOERS, Th. M.; BEN-AHER, J. A review of rainwater harvesting. Agricultural Water Management, Agricultural Water Management, v. 5, p.145-158, 1982.

BRASIL, MINISTÉRIO DA SAÚDE: Portaria nº 518 de 25 de março de 2004. Diário Oficial da União, Brasilia, p. 1-15, 2004.

BRASIL. MINISTÉRIO DO MEIO AMBIENTE. CONSELHO DO MEIO AMBIENTE: Resolução nº 357 de 17 de março de 2005. Diário oficial da União, Brasilia, p. 1-23, 2005.

FENDRICH, R. Coleta, armazenamento, utilização e infiltração das águas pluviais na drenagem urbana, Tese (Doutorado em Geologia Ambiental). Universidade Federal do Paraná, Paraná, 2002.

GHISI, E. e OLIVEIRA, S.M. de. Potential for potable water savings by combining the use of rainwater and greywater in houses in southern Brazil. Elsevier, Building and Environment, v. 42, p. 1731-1742, 2007.

GHISI, E; BRESSAN D. L.e MARTINI M. Rainwater tank capacity and potential for potable water savings by using rainwater in the residential sector of southeastern Brazil. Elsevier, Building and Environment, v. 42, p. 1654-1666, 2007.

HERRMANN, T.; SCHMIDA, U. Rainwater utilisation in Germany: efficiency, dimensioning, hydraulic and environmental aspects. Urban Water, Hannover, v.1, n.4, p. 307-316, 1999.

JAQUES, R.C. et al. Qualidade da Água de Chuva no Município de Florianópolis e sua Potencialidade para Aproveitamento em Edificações. In: VIII SIMPÓSIO ITTALO BRASILEIRO DE ENGENHARIA SANITÁRIA E AMBIENTAL, 17 a 22 de setembro de 2006, Fortaleza. Anais... Fortaleza, CE. Associação Brasileira de Engenharia Sanitária e Ambiental (ABES). CD-ROM.

KOBIYAMA, M., HANSEN, S. Vantagens da utilização do sistema de coleta da água da chuva sob o ponto de vista dos aspectos hidrológicos e econômicos: Estudo de caso em Florianópolis/SC. In: _ GROUP RAINDROPS. Aproveitamento da água da chuva. Organizadores e Tradutores: KOBIYAMA, M., USHIWATA, C. T., AFONSO, M. Curitiba/PR. 2002. pg.169-181.

LOPES, J.E.G.; Santos, R.C.P. Capacidade de reservatórios, 2002. Disponível em:<http://www.fcth.br/public/cursos/phd5706/phd5706_reservatorios.pdf> Acesso em : 15 dezembro de 2005.

MAY, Simone. Estudo da viabilidade do aproveitamento de água de chuva para consumo não potável em edificações. 2004. 189 pg. Dissertação (Mestrado em Engenharia Civil). Escola Politécnica da Universidade de São Paulo, São Paulo, 2004.

MCMACHON, T. Hydrology Designn for Water Use. In__ DAVID MAIDMENT. Handbook of Hydrology, 1993.

MIERZWA, J.C. et al. Águas pluviais: método de cálculo do reservatório e conceitos para um aproveitamento adequado. Revista de Gestão de Água da América Latina (REGA), Porto Alegre, Vol. 4, n 1, pg. 29-37, jan.jun. 2007

OLIVEIRA, Y. V. Uso do Balanço Hídrico Seriado para o Dimensionamento de Estrutura de Armazenamento de Água das Chuvas: Estudos de casos. 2004, 146 pg. Dissertação (Mestrado em Engenharia Ambiental). Universidade Federal de Santa Catarina, Florianópolis/SC, 2004.

PETERS, M.R., Potencialidade de uso de fontes alternativas de água para fins não potáveis em uma unidade residencial. 2006, 109 pg. Dissertação (Mestrado em Engenharia Ambiental). Universidade Federal de Santa Catarina, Santa Catarina, 2006.

SEEGER, L.M.K.; PAIVA, E.M.C.; SARI, V. Análise Comparativa do Sistema de Aproveitamento da Água da Chuva entre Duas Cidades da Região Sul e Centro-Oeste. In: XVII SIMPÓSIO BRASILEIRO DE RECURSOS HÍDRICOS E $8^{\circ}$ SIMPÓSIO DE HIDRÁULICAE RECURSOS HÍDRICOS DOS PAÍSES DE LÍNGUA OFICIAL PORTUGUESA, 25 a 29 de Novembro de 2007, São Paulo. Anais... São Paulo/ SP, 2007. Associação Brasileira de Recursos Hídricos (ABRH). CD-ROM.

SILVA, A. R.V.;TASSI, R. Dimensionamento e Simulação do Comportamento de um Reservatório para Aproveitamento de Água da Chuva: Resultados Preliminares. In: XVI SIMPÓSIO BRASILEIRO DE RECURSOS HÍDRICOS, 20 a 24 de novembro de 2005. João Pessoa. Anais.... João Pessoa/PB, 2005. Associação Brasileira de Recursos Hídricos (ABRH). CD-ROM.

TOMAZ, Plínio. Aproveitamento de água de chuva. São Paulo: Editora Navegar, 2003. 180p.

Vanessa Sari Mestranda Universidade Federal de Santa Maria/UFSM. E-mail: sari.vanessa@yahoo.com.br

Lília Mayumi Kaneda Seeger Mestre Universidade Federal de Santa Maria/ UFSM).E-mail: liakaneda@yahoo.com.br

Eloiza Maria Cauduro Dias de Paiva Professor Associado - Universidade Federal de Santa Maria/ UFSM. E-mail: eloizadepaiva@gmail.com

Ana Lúcia Denardin da Rosa Professor Assistente - Fundação Universidade Federal de Rondônia/UNIR. E-mail: eng.analucia@yahoo.com.br 